\title{
Effect of L-arginine supplementation on the hepatic phosphatidylinositol 3-kinase signaling pathway and gluconeogenic enzymes in early intrauterine growth-restricted rats
}

\author{
KAIJU LUO, PINGYANG CHEN, SUPING LI, WEN LI, MINGFENG HE, TAO WANG and JUNCAO CHEN \\ Division of Neonatology, Children's Medical Center, The Second Xiangya Hospital, \\ Central South University, Changsha, Hunan 410011, P.R. China
}

Received May 16, 2016; Accepted March 24, 2017

DOI: $10.3892 / \mathrm{etm} .2017 .4731$

\begin{abstract}
The present study aimed to investigate the response of the phosphatidylinositol 3-kinase (PI3K) signaling pathway and gluconeogenic enzymes in intrauterine growth-restricted rats to dietary L-arginine (L-Arg) supplementation during the lactation period early in life. Pregnant Sprague-Dawley rats were randomly divided into a control group (CON), an intrauterine growth restriction group (IUGR) and an L-Arg group (LA). The pregnant rats in the CON group were fed a $21 \%$ protein diet, and those in the IUGR and LA groups were fed a $10 \%$ low protein diet, and all rats were fed a $21 \%$ protein diet after delivery. Water was available ad libitum to the pregnant rats during the 21-day lactation period, and the water provided to the LA group included $200 \mathrm{mg} / \mathrm{kg} /$ day L-Arg. Blood glucose, serum insulin, homeostasis model of assessment for insulin resistance (HOMA-IR), PI3K and protein kinase B (PKB) protein expression, and phosphoenolpyruvate carboxykinase (PEPCK) and glucose-6-phosphatase (G-6-Pase) mRNA expression in the offspring rats were measured postnatally at 1,3 and 8 weeks. No significant difference in blood glucose, serum insulin and HOMA-IR were identified at any time point among the three groups. PI3K and PKB expression was lower in the IUGR group offspring compared with that in the CON group offspring, but both were increased by dietary L-Arg supplementation. PEPCK mRNA and G-6-Pase mRNA expression levels in the offspring of the IUGR group were higher compared with those in the $\mathrm{CON}$ group but were downregulated following L-Arg supplementation. These results suggest that dietary L-Arg supplementation during the early lactation period promoted catch-up growth and reversed
\end{abstract}

Correspondence to: Dr Pingyang Chen, Division of Neonatology, Children's Medical Center, The Second Xiangya Hospital, Central South University, 139 Middle Renmin Road, Changsha, Hunan 410011, P.R. China

E-mail: pingyangchen@126.com

Key words: L-arginine, phosphatidylinositol 3-kinase, protein kinase B, gluconeogenic enzymes, intrauterine growth restriction, rat abnormalities in hepatic insulin signaling and gene expression of gluconeogenic enzymes in IUGR offspring rats.

\section{Introduction}

Intrauterine growth restriction (IUGR) is a common complication of pregnancy that results in fetal/neonatal morbidity. Epidemiological and animal studies have closely linked IUGR with adult metabolic syndrome (MS), which includes type 2 diabetes, central obesity, hypertension and hyperlipemia (1-3). However, the basic mechanism for the later development of MS has not been fully uncovered, and insulin resistance (IR) is hypothesized to be a key physiopathological process (4). The liver is sensitive to insulin, and hepatic IR leads to dysfunction in glucose intake and utilization. In hepatic cells, insulin-binding insulin receptor substrate (IRS) proteins produce biological effects through the phosphatidylinositol 3-kinase (PI3K) signaling pathway (5). As a direct target protein of PI3K, protein kinase $\mathrm{B}(\mathrm{PKB})$ may participate in hepatic growth and differentiation and glucose metabolism (6). Gluconeogenesis is primarily modulated by phosphoenolpyruvate carboxykinase (PEPCK) and glucose-6-phosphatase (G-6-Pase) (7). An impaired hepatic insulin signaling pathway reduces the inhibitory effect of glucose of the gene transcription of gluconeogenic enzymes, including PEPCK and G-6-Pase, which increases gluconeogenesis and induces IR (8).

Nutrients are important regulators of gene transcription and translation, and control metabolic status and metabolites (9). In undernourished mothers, supplementation of the maternal diet with L-arginine (L-Arg) promotes fetal growth and ameliorates IUGR $(10,11)$. In addition, dietary supplementation with L-Arg in animal models of diabetes reduces body weight and blood glucose levels (12). However, most studies of dietary L-Arg intervention have involved implementation during intrauterine life or adult disease models, and very few have addressed the question of whether L-Arg supplementation in the early postnatal period could be a nutritional strategy for combating IUGR, particularly by reversing IR caused by a maternal protein-restricted diet.

A previous study showed that L-Arg supplementation in early pregnancy was able to stimulate PI3K protein expression in skeletal muscle and PKB phosphorylation (13). However, it is 
unclear whether L-Arg intervention during the early lactation period in rats affected by IUGR has a positive effect on later hepatic IR. This aim of the present study was to investigate the role of PI3K signaling in maternal malnutrition programming and determine whether dietary L-Arg supplementation during early life is able to alleviate the negative effects of IR caused by IUGR in offspring.

\section{Materials and methods}

Rats and experimental design. The experimental protocols were approved by the Experimental Animal Center of the Second Xiangya Hospital of Central South University (Changsha, China). A total of 18 male and 18 female 3-month-old Sprague-Dawley (SD) rats (weighing 250-300 g) were included in this study. This study was carried out in strict accordance with the recommendations in the Guide for the Care and Use of Laboratory Animals of the National Institutes of Health. The animal use protocol has been reviewed and approved by the Institutional Animal Care and Use Committee (IACUC) of Central South University. The male and female rats were placed in individual cages at a ratio of $1: 1$. When a vaginal plug was observed in the female, that day was designated as gestation day 1. Pregnant rats were randomly divided into a control group $(\mathrm{CON})$, an IUGR group (IUGR) and an L-Arg group (LA). The establishment of the IUGR model was conducted as described in our previous studies with modifications $(14,15)$. The pregnant rats in the CON group were fed a $21 \%$ protein diet (normal feed) and normal water during pregnancy and lactation. The pregnant rats in the IUGR group were fed a $10 \%$ protein diet (protein-restricted feed) only during pregnancy and a $21 \%$ protein diet (normal feed) and normal water during lactation. The pregnant rats in the LA group were fed protein-restricted feed during pregnancy, and normal feed and water supplemented with L-Arg $200 \mathrm{mg} / \mathrm{kg} /$ day during lactation. At weaning on postnatal day 21 , the offspring of the three groups were all given normal feed and normal water for 8 weeks; this time period was specifically selected to represent the juvenile-pubertal period (16). The animals were housed in a room with temperature of $21-22^{\circ} \mathrm{C}$, humidity of $50-70 \%$ and a $12 \mathrm{~h}$ light/dark cycle. The composition of the diet was as previously described (14). There were 8-10 offspring in each nest during lactation, and nests with $>14$ offspring or $<8$ offspring were excluded. For 6 offspring rats, body weight was measured and blood samples and hepatic tissue samples were collected at of 1, 3 and 8 weeks of age. Postnatal week 3 was set as the weaning point and the end of the intervention. Liver samples were taken $<5$ min after sacrifice, separated into two parts and snap-frozen in liquid nitrogen prior to being stored at $-80^{\circ} \mathrm{C}$ for later use in western blotting and reverse transcription- polymerase chain reaction (RT-PCR) assays.

Blood glucose and biochemical measurements. Prior to sacrificing the rats at each time point, blood glucose was measured after a 1-h fast using cut tail tips with an Accu-Chek Blood Glucose Meter (Roche Diagnostics GmbH, Mannheim, Germany). Serum insulin was measured using a competitive radioimmunoassay (INS RIA kit; catalogue number RC-01-01;
3V Bio Engineering Co., Ltd., Weifang, China). IR was calculated according to the homeostasis model of assessment for insulin resistance (HOMA-IR) (17).

Western blot analysis. Hepatic tissues were homogenized in ice-cold radioimmunoprecipitation assay buffer containing protease and phosphatase inhibitor cocktails (EMD Millipore, Billerica, MA, USA). The concentration of total protein was determined using a Bicinchoninic acid protein assay kit according to the manufacturer's protocol (cat. no. P0012, Beyotime Institute of Biotechnology, Haimen, China). Total protein $(20 \mathrm{mg})$ samples were separated on $10 \%$ SDS-polyacrylamide gels and transferred onto polyvinylidene difluoride membranes (EMD Millipore). The membranes were blocked with $1 \%$ bovine serum albumin (Fuzhou Maixin Biotech Co., Ltd., Fuzhou, China) for $1 \mathrm{~h}$ at room temperature (RT). Blots were incubated with PI3K p85 (19H8) rabbit $\mathrm{mAb}$ and $\mathrm{PKB}$ (11E7) rabbit $\mathrm{mAb}$ (catalogue number 4257; 1:1,000; Cell Signaling Technology, Inc., Danvers, MA, USA) at $4^{\circ} \mathrm{C}$ for $2 \mathrm{~h}$. Anti- $\beta$-actin antibody $(1: 1,000$, catalogue number ab8226, Abcam, Cambridge, MA, USA) was used as internal reference. The primary antibodies were detected using horseradish peroxidase-conjugated goat anti-rabbit IgG antibody (catalogue number 95058-730; 1:1,000; KPL, Inc., Gaithersburg, MD, USA) with incubation at $4^{\circ} \mathrm{C}$ for $2 \mathrm{~h}$. Bands were visualized using enhanced chemiluminescence (KPL, Inc.). Bands were scanned and protein expression quantified using Quantity One software (v4.62; Bio-Rad Laboratories, Inc., Hercules, CA, USA).

$R T-P C R$. Total RNA was isolated from the hepatic tissue of the rat pups using TRIzol reagent (Thermo Fisher Scientific, Inc., Waltham, MA, USA) according to the user manual provided with the reagent. RT was performed using a One Step PrimeScript $^{\circledR}$ RT kit (Thermo Fisher Scientific, Inc.). The RT reaction condition was $37^{\circ} \mathrm{C}$ for $15 \mathrm{~min}$, followed by $85^{\circ} \mathrm{C}$ for $5 \mathrm{sec}$, and the reaction system ( $20 \mu \mathrm{l}$ for each sample) was as follows: PrimeScript Buffer (5x), $4 \mu \mathrm{l}$; PrimeScript RT Enzyme Mix I, $1 \mu \mathrm{l}$; Oligo Dt Primer (50 $\mu \mathrm{mol} / \mathrm{l}), 1 \mu \mathrm{l}$; Random 6 mers (100 $\mu \mathrm{mol} / \mathrm{l}), 1 \mu \mathrm{l}$; total RNA, $13 \mu \mathrm{l}$. The rat PEPCK gene was amplified using the forward primer 5'-GGGTGGACCTCC TGTGGACT-3' and the reverse primer 5'-GGCTTCAGCGAG TCAAAGAGA-3'. The rat G-6-Pase gene was amplified using the forward primer 5'-GCCCAAGATCTTCCACGTCA-3' and the reverse primer 5'-CGATCTCCTCCACCTCCTTC-3'. The $\beta$-actin gene was amplified as an internal control using the forward primer 5'-TCCTCCCTGGAGAAGAGCTA-3' and the reverse primer 5'-TCAGGAGGAGCAATGATC TTG-3'. The PCR system (15 $\mu$ l for each sample) was as follows: Premix Ex Taq (2x), $7.5 \mu \mathrm{l}$; forward primer $(10 \mu \mathrm{mol} / \mathrm{l})$, $0.25 \mu \mathrm{l}$; reverse primer $(10 \mu \mathrm{mol} / \mathrm{l}), 0.25 \mu \mathrm{l}$; cDNA $(5 \mathrm{ng} / \mu \mathrm{l})$, $3 \mu \mathrm{l} ; \mathrm{dH}_{2} \mathrm{O}, 4 \mu \mathrm{l}$. Primers were designed and synthesized by Shanghai Invitrogen Biotechnology Co., Ltd. (Shanghai, China; Table I). After initial denaturation of $15 \mathrm{~min}$ at $95^{\circ} \mathrm{C}$, the PCR condition was as follows: for TNF- $\alpha, 50$ cycles of $95^{\circ} \mathrm{C}$ for $15 \mathrm{sec}, 61^{\circ} \mathrm{C}$ for $15 \mathrm{sec}$, and $72^{\circ} \mathrm{C}$ for $15 \mathrm{sec}$; for VEGF, 40 cycles of $95^{\circ} \mathrm{C}$ for $10 \mathrm{sec}, 58^{\circ} \mathrm{C}$ for $15 \mathrm{sec}$, and $72^{\circ} \mathrm{C}$ for $10 \mathrm{sec}$. PCR products were separated by $5 \%$ agarose gel electrophoresis followed by analysis using a LabWork 4.0 image analysis system (Labworks Inc., NY, USA). The expressions of 
Table I. Baseline characteristics of the study groups in the perinatal period.

\begin{tabular}{lcccccc}
\hline Group & $\begin{array}{c}\text { Pregnant } \\
\text { rats, } n\end{array}$ & $\begin{array}{c}\text { Total } \\
\text { offspring, } \mathrm{n}\end{array}$ & $\begin{array}{c}\text { Mean offspring } \\
\text { per litter, } \mathrm{n}^{\mathrm{a}}\end{array}$ & $\begin{array}{c}\text { Mean birth weight of } \\
\text { offspring rats, } \mathrm{g}^{\mathrm{a}}\end{array}$ & $\begin{array}{c}\text { LBW offspring } \\
\text { rats, }(\%)^{\mathrm{b}}\end{array}$ & $\begin{array}{c}\text { Prenatal } \\
\text { mortality, } \mathrm{n}(\%)^{\mathrm{b}}\end{array}$ \\
\hline CON & 6 & 65 & $10.8 \pm 1.72$ & $6.98 \pm 0.44$ & $2(3.08)$ & $1(1.54)$ \\
IUGR & 4 & 43 & $10.7 \pm 2.06$ & $6.09 \pm 0.50^{\mathrm{c}}$ & $30(69.76)^{\mathrm{c}}$ & $4(9.30)$ \\
LA & 4 & 44 & $11.0 \pm 1.41$ & $5.92 \pm 0.61^{\mathrm{c}}$ & $30(68.18)^{\mathrm{c}}$ & $0(0)$ \\
F $\left(\chi^{2}\right)$ & & & 1.213 & 5.151 & 66.897 & 3.530 \\
P-value & & & 0.979 & $<0.001$ & $<0.001$ & 0.113 \\
\hline
\end{tabular}

Comparisons using ${ }^{\mathrm{a}} \mathrm{F}$ statistics or ${ }^{\mathrm{b}} \mathrm{Chi}$-square test. ${ }^{\mathrm{c}} \mathrm{P}<0.01$ compared with the $\mathrm{CON}$ group. CON, control; IUGR, intrauterine growth restriction; LA, L-arginine supplemented IUGR; LBW, low birth weight.

Table II. Comparison of body weight, blood glucose, serum insulin and HOMA-IR of offspring among the three groups.

\begin{tabular}{|c|c|c|c|c|c|}
\hline Variable & $\mathrm{CON}$ & IUGR & LA & $\mathrm{F}$ & P-value \\
\hline \multicolumn{6}{|c|}{ Body weight, g } \\
\hline 1 week & $14.76 \pm 3.46$ & $10.99 \pm 0.44^{\mathrm{a}}$ & $12.46 \pm 1.56^{\mathrm{a}, \mathrm{b}}$ & 23.190 & $<0.001$ \\
\hline 3 weeks & $36.58 \pm 9.77$ & $28.53 \pm 8.08^{\mathrm{a}}$ & $36.38 \pm 6.62^{b}$ & 7.194 & 0.002 \\
\hline 8 weeks & $162.67 \pm 29.64$ & $99.05 \pm 18.83^{\mathrm{a}}$ & $128.42 \pm 30.68$ & 12.554 & $<0.001$ \\
\hline \multicolumn{6}{|c|}{ Blood glucose, mmol/l } \\
\hline 1 week & $5.53 \pm 0.51$ & $5.42 \pm 0.69$ & $5.64 \pm 0.52$ & 1.766 & 0.175 \\
\hline 3 weeks & $5.52 \pm 1.05$ & $5.73 \pm 1.39$ & $5.99 \pm 0.73$ & 0.905 & 0.410 \\
\hline 8 weeks & $5.40 \pm 1.30$ & $5.43 \pm 1.26$ & $5.17 \pm 1.68$ & 0.002 & 0.998 \\
\hline \multicolumn{6}{|c|}{ Serum insulin, mIU/1 } \\
\hline 1 week & $119.62 \pm 21.73$ & $117.11 \pm 42.25$ & $118.2 \pm 36.50$ & 0.008 & 0.992 \\
\hline 3 weeks & $82.75 \pm 17.07$ & $81.52 \pm 22.52$ & $79.80 \pm 22.70$ & 0.030 & 0.970 \\
\hline 8 weeks & $38.96 \pm 18.77$ & $39.94 \pm 19.28$ & $36.80 \pm 5.60$ & 0.062 & 0.941 \\
\hline \multicolumn{6}{|l|}{ HOMA-IR } \\
\hline 1 week & $3.36 \pm 0.17$ & $3.28 \pm 0.46$ & $3.31 \pm 0.40$ & 0.073 & 0.930 \\
\hline 3 weeks & $3.00 \pm 0.30$ & $3.01 \pm 0.39$ & $3.02 \pm 0.33$ & 0.005 & 0.995 \\
\hline 8 weeks & $2.12 \pm 0.65$ & $2.18 \pm 0.26$ & $2.07 \pm 0.40$ & 0.078 & 0.925 \\
\hline
\end{tabular}

${ }^{\mathrm{a}} \mathrm{P}<0.05$ compared with the CON group, ${ }^{\mathrm{b}} \mathrm{P}<0.05$ compared with the IUGR group. CON, control; IUGR, intrauterine growth restriction; LA, L-arginine supplemented IUGR; HOMA-IR, homeostasis model of assessment for insulin resistance.

PEPCK and G-6-Pase mRNA were presented by the ratio of optical density of target gene to $\beta$-actin.

Statistical analysis. Data were analyzed using SPSS version 13.0 (SPSS, Inc., Chicago, IL, USA). All results are shown as the mean \pm standard deviation. Statistical significance of the differences among the three groups was determined by analysis of variance, followed by least significant difference test. The $\chi^{2}$ test was performed to detect differences in the proportions of categorical variables. $\mathrm{P}<0.05$ was considered to indicate a statistically significant result.

\section{Results}

IUGR model establishment. After continuous mating for 14 days, 14 female rats became pregnant All pregnant rats went into labor on gestation days 21-23, without miscarriage. Table I shows the baseline characteristics of the CON, IUGR and LA groups during the perinatal period. There was no difference in the average litter size among the groups. The body weight of offspring was significantly lower in the IUGR and LA groups compared with that in the $\mathrm{CON}$ group $(\mathrm{P}<0.01)$, which was accompanied by a higher incidence of low-birth-weight (LBW) offspring rats. LBW was defined as less than the average birth weight of the offspring rats in the CON group minus two standard deviations (18).

Measures of body weight, blood glucose, serum insulin and HOMA-IR after birth. Table II presents a comparison of the body weight and blood glucose levels in the three groups at postnatal weeks 1, 3 and 8. Compared with the offspring in the CON group, body weight was significantly lower in the IUGR group at all time points. Body weight in the LA group at 1 week was lower than that in the CON group but higher 
Table III. Comparison of hepatic PI3K and PKB protein expression in the three groups.

\begin{tabular}{lcccrr}
\hline Protein & CON & IUGR & LA & F & P-value \\
\hline PI3K & & & & & \\
1 week & $0.647 \pm 0.029$ & $0.586 \pm 0.037^{\mathrm{a}}$ & $0.634 \pm 0.035^{\mathrm{b}}$ & 9.764 & $<0.001$ \\
3 weeks & $0.540 \pm 0.035$ & $0.493 \pm 0.033^{\mathrm{a}}$ & $0.528 \pm 0.028$ & 7.192 & 0.003 \\
8 weeks & $0.564 \pm 0.061$ & $0.490 \pm 0.049^{\mathrm{a}}$ & $0.517 \pm 0.063$ & 4.270 & 0.022 \\
PKB & & & & 1.506 & 0.237 \\
1 week & $0.758 \pm 0.049$ & $0.725 \pm 0.046$ & $0.730 \pm 0.034$ & 1.282 & 0.291 \\
3 weeks & $0.681 \pm 0.051$ & $0.653 \pm 0.040$ & $0.682 \pm 0.062$ & 9.334 & 0.001 \\
8 weeks & $0.625 \pm 0.031$ & $0.556 \pm 0.041^{\mathrm{a}}$ & $0.618 \pm 0.050^{\mathrm{b}}$ & & \\
\hline
\end{tabular}

${ }^{\mathrm{a}} \mathrm{P}<0.05$ compared with CON group, ${ }^{\mathrm{b}} \mathrm{P}<0.05$ compared with IUGR group. CON, control; IUGR, intrauterine growth restriction; LA, L-arginine supplemented IUGR; PI3K, phosphatidylinositol 3-kinase; PKB, protein kinase B.

Table IV. Comparison of hepatic PEPCK and G-6-Pase mRNA expression among the three groups.

\begin{tabular}{|c|c|c|c|c|c|}
\hline mRNA & $\mathrm{CON}$ & IUGR & LA & $\mathrm{F}$ & $\mathrm{P}$-value \\
\hline \multicolumn{6}{|l|}{ PEPCK } \\
\hline 1 week & $0.37 \pm 0.09$ & $0.44 \pm 0.08$ & $0.42 \pm 0.06$ & 1.255 & 0.313 \\
\hline 3 weeks & $0.90 \pm 0.04$ & $1.09 \pm 0.13^{\mathrm{a}}$ & $0.94 \pm 0.11^{b}$ & 6.230 & 0.011 \\
\hline 8 weeks & $1.29 \pm 0.07$ & $2.40 \pm 0.12^{\mathrm{a}}$ & $2.23 \pm 0.14^{\mathrm{a}, \mathrm{b}}$ & 165.872 & $<0.001$ \\
\hline \multicolumn{6}{|l|}{ G-6-Pase } \\
\hline 1 week & $0.81 \pm 0.12$ & $1.09 \pm 0.04^{\mathrm{a}}$ & $1.03 \pm 0.08^{\mathrm{a}}$ & 19.003 & $<0.001$ \\
\hline 3 weeks & $1.23 \pm 0.15$ & $1.85 \pm 0.08^{\mathrm{a}}$ & $1.24 \pm 0.15^{\mathrm{b}}$ & 43.172 & $<0.001$ \\
\hline 8 weeks & $1.36 \pm 0.04$ & $2.24 \pm 0.14^{\mathrm{a}}$ & $1.89 \pm 0.07^{\mathrm{a}, \mathrm{b}}$ & 134.742 & $<0.001$ \\
\hline
\end{tabular}

${ }^{\mathrm{a}} \mathrm{P}<0.05$ compared with the CON group, ${ }^{\mathrm{b}} \mathrm{P}<0.05$ compared with the IUGR group. CON, control; IUGR, intrauterine growth restriction; LA, L-arginine supplemented IUGR; PEPCK, phosphoenolpyruvate carboxykinase; G-6-Pase, glucose-6-phosphatase.

than that in the IUGR group. Body weight in the LA group was not significantly different from that in the CON group at 3 weeks. There was no significant difference in blood glucose, serum insulin and HOMA-IR at any time point among the three groups. Serum insulin decreased gradually with age in the three groups.

Hepatic PI3K and PKB protein expression. A comparison of hepatic PI3K and PKB protein expression at postnatal weeks 1, 3 and 8 among the three groups is shown in Table III. PI3K expression was significantly lower in the IUGR group compared with that in the CON group at all time points. Expression of PI3K protein in the LA group at 1 week was higher than that in the IUGR group, and there was no difference between the CON and LA groups at this time point. At 3 and 8 weeks, PI3K expression levels in the LA group were between those of the CON and IUGR groups, and there was no significant difference between the LA and IUGR groups or between the LA and CON groups. PKB protein expression did not differ among the three groups at 1 and 3 weeks, while at 8 weeks, expression of PKB in the IUGR group was lower than that in the CON group; in the LA group, PKB protein expression was higher compared with that in the IUGR group and was not different compared with that in the CON group (Table III and Fig. 1).
Hepatic PEPCK mRNA and G-6-Pase mRNA expression. A comparison of hepatic PEPCK and G-6-Pase mRNA expression at postnatal weeks 1, 38 among the three groups is shown in Table IV. PEPCK mRNA expression in the IUGR group was higher than that in the CON group at 3 and 8 weeks. PEPCK mRNA expression at 3 weeks in the LA group was lower than that in the IUGR group and was not different from that in the CON group. At 8 weeks in the LA group, PEPCK mRNA expression remained lower than in the IUGR group but higher than in the CON group. G-6-Pase mRNA expression was higher in the IUGR group than in the CON group at all time points. At 1 week, G-6-Pase mRNA expression in the LA group was higher compared with that in the CON group and was not different from that in the IUGR group. At 3 weeks in the LA group, G-6-Pase mRNA expression was lower compared with that in the IUGR group and was not different from that in the CON group. At 8 weeks, G-6-Pase mRNA expression in the LA group was lower than that in the IUGR group but higher than that in the CON group (Table IV and Fig. 2).

\section{Discussion}

As a strong risk factor of IR, IUGR is associated with an increased risk of MS in adulthood $(1,19)$. In the present study, an IUGR rat 


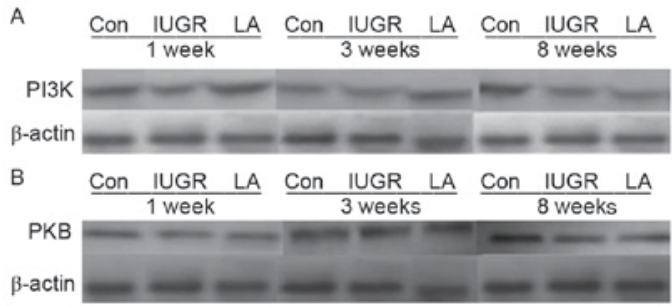

Figure 1. Hepatic (A) PI3K and (B) PKB protein expression in the three groups. PI3K, phosphatidylinositol 3-kinase; PKB, protein kinase B; IUGR, intrauterine growth restriction; LA, L-arginine supplemented IUGR.

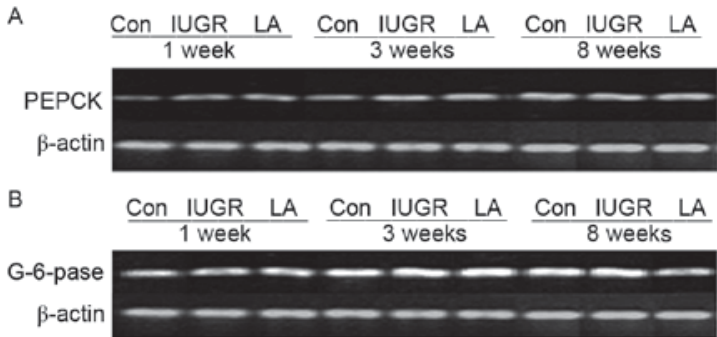

Figure 2. Hepatic (A) PEPCK mRNA and (B) G-6-Pase mRNA expression in the three groups. PEPCK, phosphoenolpyruvate carboxykinase G-6-Pase, glucose-6-phosphatase; IUGR, intrauterine growth restriction; LA, L-arginine supplemented IUGR.

model was established by restricting maternal protein during pregnancy and it was observed that IUGR-affected pups had a consistently lower body weight compared with the CON group from birth to postnatal week 8 (considered the pubertal period) and did not experience catch-up growth. The present study also showed that IUGR pups had no peripheral signs of obesity and diabetes development, such as evident IR, weight gain and increased blood glucose, up to 8 weeks. Simmons et al (20) also observed no significant difference in blood glucose and plasma insulin levels at 1 week but reported mild fasting hyperglycemia and hyperinsulinemia between 7 and 10 weeks and markedly elevated levels of glucose at 26 weeks in IUGR rats. Vo et al (21) demonstrated glucose intolerance in rats with low protein-induced IUGR at 4 months. The reason that catch-up growth, high blood glucose and IR developed at different postnatal times in the IUGR animal models in the literature may be due to different modeling methods, animal species, raising conditions and observation times. The distinct biochemical abnormality in IUGR often manifests in adulthood, whereas IR is already present early in life $(22,23)$, which suggests that molecular-level factors may be the predictors of adult MS.

Although rats with IUGR did not exhibit evident physical functional changes in early life, 'adaptive changes' at the cell or gene level may have already occurred. In the present study, hepatic PI3K protein expression in the rats of the IUGR group was consistently lower compared with that in $\mathrm{CON}$ rats from postnatal week 1, and decreased PKB protein expression began at 8 weeks, indicating that rats with IUGR had an abnormal insulin signaling pathway. Thus, PI3K and PKB protein expression decreased in the rats with IUGR, and the abnormality in PI3K preceded that in PKB. Moreover, PEPCK mRNA expression was upregulated at 3 weeks and G-6-Pase mRNA expression was increased at 1 week, which suggested that abnormal gene transcription of gluconeogenic enzymes in pups with IUGR emerged early in postnatal life. PI3K and PKB are important proteins in the hepatic insulin signaling pathway, and PKB is the direct target protein of the insulin receptor and PI3K. The abnormal expression of PI3K and PKB may influence the normal process of hepatic insulin signal transduction and glucose transfer, eventually resulting in hepatic IR $(8,20)$. PEPCK and G-6-Pase are key rate-limiting enzymes of glyconeogenesis and are regulated at the transcriptional level. Changes in PEPCK mRNA reflect PEPCK activity and the glyconeogenic rate. Studies have shown that decreased PKB protein expression in skeletal muscle inhibits the transport of glucose transporter 4 and reduces insulin-mediated glucose uptake and glycolysis $(24,25)$. In the present study, PKB protein expression was not obviously abnormal until puberty, at which time PKB activation became a serious obstacle to insulin stimulation and then affected the further transmission of insulin signaling. In addition, the downregulation of PI3K and PKB proteins may upregulate the gene transcription of PEPCK and G-6-Pase, increase the expression of PEPCK mRNA and G-6-Pase mRNA, and result in glyconeogenesis and increased blood glucose, further exacerbating IR. However, previous studies in rats emphasized that the overexpression of the PEPCK gene and altered signal transduction downstream of the insulin receptor represented the most likely mechanism of increased glycogen production in IR, which was responsible for diabetes. Sun et al (26) showed that PEPCK overexpression in transgenic mice resulted in a selective reduction in IRS-2 protein, decreased PI3K activity, and reduced the ability of insulin to suppress gluconeogenic gene expression. Vuguin et al (27) showed that PEPCK and G-6-Pase mRNA levels were increased in the livers of rats with IUGR, suggesting that insulin signaling is impaired in the IUGR liver and that gluconeogenesis is augmented in IUGR rats prior to the onset of hyperglycemia, which was consistent with the animal model in the present study.

Nutritional programming is the hypothesis that a stimulus or insult during a critical or sensitive period of development can have long-term or lifetime effects on an organism $(28,29)$. Currently, L-Arg is used in the treatment of adult diabetes. To our knowledge, although the effect of L-Arg administration during pregnancy on fetal growth and development has been investigated in previous studies, the effects of exogenous L-Arg are unclear. For example, Satterfield et al (30) indicated that L-Arg administration to nutrient-restricted maternal sheep enhanced fetal pancreatic and brown adipose tissue development. Sieroszewski et al (11) demonstrated that L-Arg administration to pregnant women with growth restriction may improve fetal growth and increase birth weight. However, the study performed by Winer et al (31) indicated that L-Arg was not an effective treatment for severe vascular growth restriction. In the present study, the effect of L-Arg supplementation in early postnatal rats on the hepatic PI3K signaling pathway and gluconeogenic enzymes was first examined. L-Arg was administered to rats with IUGR in early life during the lactation period, and it was observed that L-Arg promoted body weight gain and catch-up growth in LA rats with no abnormalities in blood glucose, serum insulin, HOMA-IR and peripheral IR. It was also observed that after 1 week of L-Arg supplementation, PI3K protein expression in the livers of LA rats increased, and PKB protein expression in the livers of LA rats was subsequently upregulated at 8 weeks. Furthermore, PEPCK and G-6-Pase mRNA 
in the LA group decreased from postnatal week 3. Notably, L-Arg supplementation in early life increased hepatic PI3K and PKB protein expression, downregulated PEPCK and G-6-Pase gene transcription, improved insulin signaling and glucose metabolism, and reduced gluconeogenesis. L-Arg administration was stopped at 3 weeks when the rats were weaned. At that time point, body weight gain and PEPCK and G-6-Pase mRNA expression in the rats that received supplementation had changed markedly to approximately the normal levels; however, after stopping L-Arg supplementation, the changes weakened, which suggested that the intervention time should be extended or the intervention dose increased. Therefore, further studies are required to determine the appropriate treatment time and dose of L-Arg supplementation and explore whether L-Arg has the same positive effect on other insulin target organs.

In conclusion, the results of the present study demonstrated that decreased hepatic PI3K and PKB protein expression and increased PEPCK and G-6-Pase mRNA expression occurred early in the life of IUGR rats, which may reflect the molecular basis of hepatic IR in individuals affected by IUGR. These results suggest that dietary L-Arg supplementation during the early lactation period promoted catch-up growth and reversed the abnormalities in hepatic insulin signaling and gene expression of gluconeogenic enzymes in IUGR offspring rats. This study provides insights into approaches to ameliorate the negative effects of IUGR on offspring using nutritional strategies during the early period of life.

\section{Acknowledgements}

The present study was supported by the Planned Science and Technology Project of Hunan Province (grant no. 2014SK4067) and in part by the Youth Natural Science Foundation of Hunan Province (grant no. S2010J504B).

\section{References}

1. Salam RA, Das JK and Bhutta ZA: Impact of intrauterine growth restriction on long-term health. Curr Opin Clin Nutr Metab Care 17: 249-254, 2014

2. Breier BH, Vickers MH, Ikenasio BA, Chan KY and Wong WP: Fetal programming of appetite and obesity. Mol Cell Endocrinol 185: 73-79, 2001.

3. Gascoin G and Flamant C: Long-term outcome in context of intrauterine growth restriction and/or small for gestational age newborns. J Gynecol Obstet Biol Reprod (Pairs) 42: 911-920, 2013 (In French).

4. Lakshmy R: Metabolic syndrome: Role of maternal undernutrition and fetal programming. Rev Endocr Metab Disord 14: 229-240, 2013.

5. Cantley LC: The phosphatidylinositide-3 kinase pathway. Science 296: 1655-1657, 2002

6. Kim DK, Kim YH, Hynx D, Wang Y, Yang KJ, Ryu D, Kim KS, Yoo EK, Kim JS, Koo SH, et al: PKB/Akt phosphorylation of ERR $\gamma$ contributes to insulin-mediated inhibition of hepatic gluconeogenesis. Diabetologia 57: 2576-2585, 2014.

7. Barthel A and Schmoll D: Novel concepts in insulin regulation of hepatic gluconeogenesis. Am J Physiol Endocrinol Metab 285: E685-E692, 2003.

8. Liu TY, Shi CX, Gao R, Sun HJ, Xiong XQ, Ding L, Chen Q, Li YH, Wang JJ, Kang YM and Zhu GQ: Irisin inhibits hepatic gluconeogenesis and increases glycogen synthesis via the PI3K/Akt pathway in type 2 diabetic mice and hepatocytes. Clin Sci (Lond) 129: 839-850, 2015.

9. Berná G, Oliveras-López MJ, Jurado-Ruíz E, Tejedo J, Bedoya F, Soria B and Martín F: Nutrigenetics and nutrigenomics insights into diabetes etiopathogenesis. Nutrients 6: 5338-5369, 2014.
10. Lassala A, Bazer FW, Cudd TA, Datta S, Keisler DH, Satterfield MC, Spencer TE and Wu G: Parenteral administration of L-arginine prevents fetal growth restriction in undernourished ewes. J Nutr 40: 1242-1248, 2010.

11. Sieroszewski P, Suzin J and Karowicz-Bilińska A: Ultrasound evaluation of intrauterine growth restriction therapy by a nitric oxide donor (L-arginine). J Matern Fetal Neonatal Med 15: 363-366, 2004.

12. Kohli R, Meininger CJ, Haynes TE, Yan W, Self JT and Wu G: Dietary L-arginine supplementation enhances endothelial nitric oxide synthesis in streptozotocin-induced diabetic rats. J Nutr 134: 600-608, 2004.

13. Zeng X, Mao X, Huang Z, Wang F, Wu G and Qiao S: Arginine enhances embryo implantation in rats through $\mathrm{PI} 3 \mathrm{~K} / \mathrm{PKB} / \mathrm{mTOR} / \mathrm{NO}$ signaling pathway during early pregnancy. Reproduction 145: 1-7, 2013.

14. Xie Z, Dong Q, Ge J, Chen P, Li W and Hu J: Effect of low birth weight on impaired renal development and function and hypertension in rat model. Ren Fail 34: 754-759, 2012.

15. He X, Xie Z, Dong Q, Chen P, Hu J and Wang T: Apoptosis in the kidneys of rats that experienced intrauterine growth restriction. Nephrology (Carlton) 20: 34-39, 2015.

16. He X, Xie Z, Dong Q, Li J, Li W and Chen P: Effect of folic acid supplementation on renal phenotype and epigenotype in early weanling intrauterine growth retarded rats. Kidney Blood Press Res 40: 395-402, 2015.

17. Mahmoud AA, Bakir AS and Shabana SS: Serum TGF- $\beta$, Serum MMP-1, and HOMA-IR as non-invasive predictors of fibrosis in Egyptian patients with NAFLD. Saudi J Gastroenterol 18: 327-333, 2012.

18. Manning $\mathbf{J}$ and Vehaskari VM: Low birth weight-associated adult hypertension in the rat. Pediatr Nephrol 16: 417-422, 2001.

19. Bavdekar A, Yajnik CS, Fall CH, Bapat S, Pandit AN, Deshpande V, Bhave S, Kellingray SD and Joglekar C: Insulin resistance syndrome in 8-year-old Indian children: Small at birth, big at 8 years, or both? Diabetes 48: 2422-2429, 1999.

20. Simmons RA, Templeton LJ and Gertz SJ: Intrauterine growth retardation leads to the development of type 2 diabetes in the rat. Diabetes 50: 2279-2286, 2001

21. Vo TX, Revesz A, Sohi G, Ma N and Hardy DB: Maternal protein restriction leads to enhanced hepatic gluconeogenic gene expression in adult male rat offspring due to impaired expression of the liver X receptor. J Endocrinol 218: 85-97, 2013.

22. Heltemes A, Gingery A, Soldner EL, Bozadjieva N, Jahr KN, Johnson BK and Gilbert JS: Chronic placental ischemia alters amniotic fluid milieu and results in impaired glucose tolerance, insulin resistance and hyperleptinemia in young rats. Exp Biol Med (Maywood) 235: 892-899, 2010

23. Zambrano E, Bautista CJ, Deás M, Martínez-Samayoa PM, González-Zamorano M, Ledesma H, Morales J, Larrea F and Nathanielsz PW: A low maternal protein diet during pregnancy and lactation has sex- and window of exposure-specific effects on offspring growth and food intake, glucose metabolism and serum leptin in the rat. J Physiol 571: 221-230, 2006.

24. Zorzano A, Palacín M and Gumà A: Mechanisms regulating GLUT4 glucose transporter expression and glucose transport in skeletal muscle. Acta Physiol Scand 183: 43-58, 2005.

25. Lai YC, Liu Y, Jacobs R and Rider MH: A novel PKB/Akt inhibitor, MK-2206, effectively inhibits insulin-stimulated glucose metabolism and protein synthesis in isolated rat skeletal muscle. Biochem J 447: 137-147, 2012.

26. Sun Y, Liu S, Ferguson S, Wang L, Klepcyk P, Yun JS and Friedman JE: Phosphoenolpyruvate carboxykinase overexpression selectively attenuates insulin signaling and hepatic insulin sensitivity in transgenic mice. J Biol Chem 277: 23301-23307, 2002.

27. Vuguin P, Raab E, Liu B, Barzilai N and Simmons R: Hepatic insulin resistance precedes the development of diabetes in a model of intrauterine growth retardation. Diabetes 53: 2617-2622, 2004.

28. Lucas A: Long-term programming effects of early nutritionimplications for the preterm infant. J Perinatol 25 (Suppl 2): S2-S6, 2005.

29. Moore SE: Early life nutritional programming of health and disease in The Gambia. J Dev Orig Health Dis 7: 123-131, 2016.

30. Satterfield MC, Dunlap KA, Keisler DH, Bazer FW and Wu G: Arginine nutrition and fetal brown adipose tissue development in nutrient-restricted sheep. Amino Acids 45: 489-499, 2013.

31. Winer N, Branger B, Azria E, Tsatsaris V, Philippe HJ, Rozé JC, Descamps P, Boog G, Cynober L and Darmaun D: L-Arginine treatment for severe vascular fetal intrauterine growth restriction: A randomized double-bind controlled trial. Clin Nutr 28: 243-248, 2009 